Article

\title{
Alanine-Scanning Mutagenesis of $\alpha$-Conotoxin GI Reveals the Residues Crucial for Activity at the Muscle Acetylcholine Receptor
}

\author{
Jiong Ning, Rui Li, Jie Ren, Dongting Zhangsun, Xiaopeng Zhu, Yong $\mathbf{W u}$ * and Sulan Luo *(D) \\ Key Laboratory of Tropical Biological Resources, Ministry of Education, Key Lab for Marine Drugs of Haikou, \\ Hainan University, Haikou 570228, Hainan, China; ningjiong2018@163.com (J.N.); flychcken@163.com (R.L.); \\ hndx2303@163.com (J.R.); zhangsundt@163.com (D.Z.); zhuxiaopeng@hainu.edu.cn (X.Z.) \\ * Correspondence: wuyong@hainu.edu.cn (Y.W.); luosulan2003@163.com (S.L.)
}

Received: 8 November 2018; Accepted: 10 December 2018; Published: 13 December 2018

check for updates

\begin{abstract}
Recently, the muscle-type nicotinic acetylcholine receptors (nAChRs) have been pursued as a potential target of several diseases, including myogenic disorders, muscle dystrophies and myasthenia gravis, etc. $\alpha$-conotoxin GI isolated from Conus geographus selectively and potently inhibited the muscle-type nAChRs which can be developed as a tool to study them. Herein, alanine scanning mutagenesis was used to reveal the structure-activity relationship (SAR) between GI and mouse $\alpha 1 \beta 1 \delta \varepsilon$ nAChRs. The $\mathrm{Pro}^{5}, \mathrm{Gly}^{8}, \mathrm{Arg}^{9}$, and $\mathrm{Tyr}^{11}$ were proved to be the critical residues for receptor inhibiting as the alanine (Ala) replacement led to a significant potency loss on mouse $\alpha 1 \beta 1 \delta \varepsilon$ nAChR. On the contrary, substituting Asn ${ }^{4}$, His ${ }^{10}$ and Ser ${ }^{12}$ with Ala respectively did not affect its activity. Interestingly, the [E1A] GI analogue exhibited a three-fold potency for mouse $\alpha 1 \beta 1 \delta \varepsilon$ $\mathrm{nAChR}$, whereas it obviously decreased potency at rat $\alpha 9 \alpha 10 \mathrm{nAChR}$ compared to wildtype GI. Molecular dynamic simulations also suggest that loop2 of GI significantly affects the interaction with $\alpha 1 \beta 1 \delta \varepsilon$ nAChR, and $\operatorname{Tyr}^{11}$ of GI is a critical residue binding with three hydrophobic amino acids of the $\delta$ subunit, including Leu ${ }^{93}, \mathrm{Tyr}^{95}$ and Leu ${ }^{103}$. Our research elucidates the interaction of GI and mouse $\alpha 1 \beta 1 \delta \varepsilon n A C h R$ in detail that will help to develop the novel analogues of GI.
\end{abstract}

Keywords: muscle-type nAChRs; $\alpha$-conotoxin GI; structure-activity relationship; electrophysiological study; molecular dynamic simulations

\section{Introduction}

Nicotinic acetylcholine receptors (nAChRs) are a member of ligand-gated ion channels that mediate the fast excitatory cholinergic neurotransmission in the central and peripheral nervous system [1-3]. In vertebrates, nAChRs are classified into muscle-type and neuronal-type nAChRs based on their primary sites of expression. The muscle-type nAChRs are found at the neuromuscular junction, and they mediate neuromuscular transmission at the neuromuscular junction (NMJ) $[4,5]$. Noticeably, muscle-type receptors from fetal muscle are composed of a combination of $\alpha 1 \beta 1 \delta \gamma$ subunits whereas those from adult muscle have the composition of $\alpha 1 \beta 1 \delta \varepsilon$ subunit. Previous research revealed that the muscle-type nAChRs were implicated in pathophysiology conditions, including myasthenia gravis, rhabdomyosarcoma, muscle dystrophies, and muscle atrophy [6-8].

Conus is a genus of marine gastropod molluscs which is estimated to have 700 different species distributing in tropical and sub-tropical oceans $[9,10]$. These gastropods armed with deadly venoms can capture worms, fishes or other mollusks. The venoms are composed of different kinds of bioactive peptides which are named as conotoxins [11,12]. Based on their conserved signal peptide sequences, the various conotoxins are classified into different super families. Further classification into 
families depends on their patterns of disulfide and pharmacological activities $[10,13,14]$. Among the conotoxins, $\alpha$-conotoxins are the most studied and targeted muscle-type or neuronal-type nAChRs with high affinity and selectivity. Typical $\alpha$-conotoxins are arranged in a CC-Xm-C-Yn-C pattern with two loops and have four cysteine residues to form two disulfide bonds with CysI-CysIII and CysI-CysIV connectivity. The first loop $\left(X_{m}\right)$ contains three or four amino acids $(m=3-4)$ and the second loop $\left(Y_{n}\right)$ consists of three to seven amino acids $(n=3-7)[15,16]$. Interestingly, most $\alpha-3 / 5$ family conotoxins block muscle-type nAChRs with high potency.

$\alpha$-conotoxin GI, which was isolated from the Conus geographus venom, is composed of 13 amino acids that selectively inhibited muscle-type nAChRs with the $\mathrm{IC}_{50}$ of $20 \mathrm{nM}[17,18]$. The structure of GI was firstly determined by two-dimensional NMR [19]. Meanwhile, several studies revealed the binding molecular mechanism between GI and muscle-type nAChRs [20,21]. Hann et al. found the 9-arginine of GI was critical for its high selectivity and activity [22], and Geobe et al. also demonstrated that $\alpha$-conotoxin [R9A] GI displayed a decrease in affinity for the two acetylcholine-binding sites on Torpedo receptors [23]. However, the role of each amino acid in $\alpha$-conotoxin GI has remained unidentified $[19,24,25]$. Nowadays, alanine scanning mutagenesis has become an effective strategy in exploring the relationship between toxins and receptors and has been applied in the $\alpha$-conotoxins pivotal residue identification [26,27].

In the present study, a series of GI analogues were synthesized and the inhibitory activity on various nAChR subunits were assessed (Figure 1). The results demonstrated that the activities retained for [N4A] GI, [H10A] GI and [S12A] GI compared to GI, whereas their potency decreased nearly more than 10-fold for [P5A] GI, [G8A] GI, [R9A] GI, and [Y11A] GI. More importantly, replacing Glu ${ }^{1}$ with an Ala led to a three-fold increase in potency at the $\alpha 1 \beta 1 \delta \varepsilon$ subtype. Further investigation revealed the interaction between $\alpha$-conotoxin GI and muscle-type nAChRs. In addition, these analogues have the potential to be developed as a molecular probe for differentiating the subtype of nAChRs $[28,29]$.

\begin{tabular}{|c|c|}
\hline Peptides & Sequences \\
\hline GI & EC C II P ACG R H Y SC \\
\hline [E1A] GI & ACCNPACGRHYSC* \\
\hline [N4A] GI & ECCAPACGRH Y C * \\
\hline [P5A] GI & ECCNAACGRHYS ${ }^{*}$ \\
\hline [G8A] GI & ECCNPACARHYSC* \\
\hline [R9A] GI & ECCNPACGAHYSC* \\
\hline [H10A] GI & E C C N P ACGRA Y S C * \\
\hline [Y11A] GI & ECCNPACGRHASC* \\
\hline$[\mathrm{S} 12 \mathrm{~A}] \mathrm{GI}$ & ECCNPACGRHYAC* \\
\hline
\end{tabular}

Figure 1. Sequences of $\alpha$-conotoxin GI and its analogues. Each substituted alanine is labeled in bold and blue. The connectivity of Cysteine (CysI-CysIII, CysII-CysIV) is marked in bold and red. * indicates a C-terminal amide.

\section{Results}

\subsection{Synthesis and Purification of GI and Its Analogues}

In this study, standard Fmoc solid phase peptide synthesis strategy was used to synthesize GI and its mutants. A two-step oxidation protocol was used to fold these peptides as described previously [30]. Briefly, CysI and CysIII were protected with S-trityl (S-Trt) while CysII and CysIV were protected with S-acetamidomethyl (S-Acm). The first disulfide bridge between CysI and CysIII was formed using the potassium ferricyanide oxidation method, and then the second disulfide bond was produced 
through iodine oxidation. All synthesized peptides were monitored by analytical Reversed-Phase High Performance Liquid Chromatography (RP-HPLC), and the purity of each analogue was above $95 \%$. Typically, the retention of the fully oxidized peptide GI and [E1A] GI is 8.82 and 8.57 min respectively, and the molecular weight of GI and [E1A] GI is 1436.50 and 1378.52 Da respectively, which are identical with the theoretical molecular weight (Figure 2). The HPLC chromatogram and ESI-MS (Electrospray ionization mass spectrometry) data of other GI analogues are provided in the Supplementary Materials' Figures S1-S3.

A

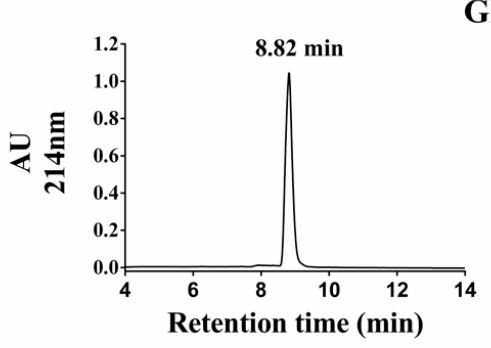

C

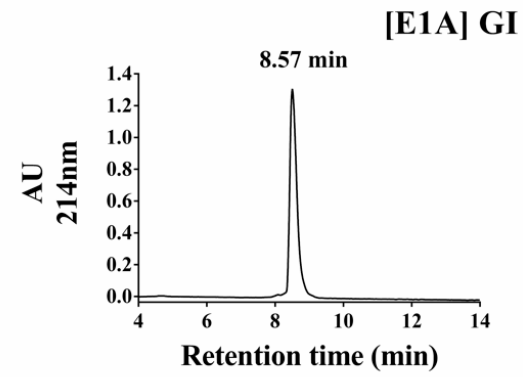

B

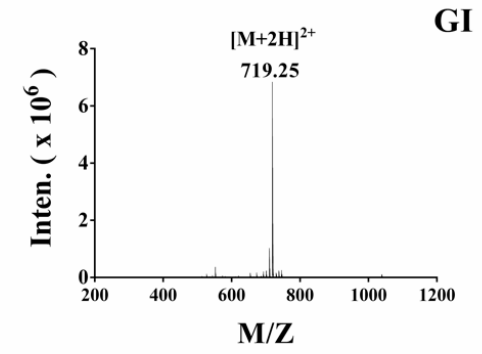

D

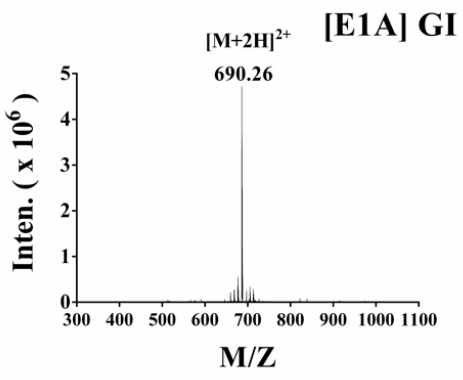

Figure 2. The HPLC and ESI-MS profiles of $\alpha$-conotoxin GI and $\alpha$-conotoxin [E1A] GI. The peptide GI and [E1A] GI were analyzed on a reverse-phase analytical Vydac C18 column with a solvent gradient from $5 \%$ buffer $\mathrm{B}$ to $40 \%$ buffer B for $20 \mathrm{~min}$ where buffer $\mathrm{A}=0.075 \%$ trifluoroacetic acid (TFA), remainder $\mathrm{H}_{2} \mathrm{O}$ and buffer $\mathrm{B}=0.050 \%$ TFA, $90 \%$ acetonitrile, remainder $\mathrm{H}_{2} \mathrm{O}$. The absorbance was monitored at $214 \mathrm{~nm}$. (A) The HPLC chromatogram of fully oxidized peptide GI; (B) ESI-MS data for GI with an observed monoisotopic mass of $1436.50 \mathrm{Da}$; (C) the HPLC chromatogram of fully folded peptide [E1A] GI; (D) ESI-MS data for [E1A] GI with an observed monoisotopic mass of 1378.52 Da.

\subsection{Potency of $\alpha$-Conotoxin GI and Its Analogues at the Mouse $\alpha 1 \beta 1 \delta \varepsilon n A C h R$}

To better understand the SAR between GI and muscle-type nAChRs, GI and all analogues were firstly tested on mouse $\alpha 1 \beta 1 \delta \varepsilon \mathrm{nAChR}$ at a single concentration of $10 \mathrm{nM}$. Figure 3 indicates that the relative amount of inhibitions are evoked by all peptides. Three analogues replacing $\mathrm{Asn}^{4}, \mathrm{His}^{10}$ and Ser ${ }^{12}$ with Ala had little effect on $\alpha 1 \beta 1 \delta \varepsilon$ nAChR compared with native GI (67\% inhibition). On the contrary, [P5A] GI and [R9A] GI substantially reduced the activity, they exhibited $21.9 \%$ and $17.6 \%$ inhibition of relative current amplitude. In addition, [G8A] GI and [Y11A] GI analogues resulted in a complete loss of inhibitory activity at the concentration of $10 \mathrm{nM}$. Notably, only one alanine substitution [E1A] GI showed a significant increase at mouse $\alpha 1 \beta 1 \delta \varepsilon$ nAChR versus GI, completely blocking muscle-type $\mathrm{nAChR}$ at the concentration of $10 \mathrm{nM}$.

We also observed that the alanine-substituted analogues affected not only the potency against $\alpha 1 \beta 1 \delta \varepsilon n A C h R$ but also its current recovery. Meanwhile, Figure 4 illustrates the effects of [Y11A] GI and [E1A] GI on mouse $\alpha 1 \beta 1 \delta \varepsilon$ nAChR-mediated current respectively. We could see that GI blockade of mouse $\alpha 1 \beta 1 \delta \varepsilon$ nAChR was $75.5 \%$ at the concentration of $10 \mathrm{nM}$, while full blocking of ACh-evoked currents was obtained with $10 \mathrm{nM}$ [E1A] GI. Additionally, the recovery time (50\% initial current) was compared between wild peptide GI and mutant [E1A] GI after the blockade by $10 \mathrm{nM}$ toxin. 
Complete recovery of [E1A] GI was observed within 4 min after $\alpha$-conotoxin [E1A] GI washout (Figure 4A) while the recovery of GI was accomplished more than 7 min after $\alpha$-conotoxin GI washout (Figure 4B). [Y11A] GI at the concentration of $10 \mu \mathrm{M}$ completely inhibited mouse $\alpha 1 \beta 1 \delta \varepsilon \mathrm{nAChR}$ and the inhibitory ACh-evoked current of [Y11A] GI was fully recovered within $2 \mathrm{~min}$ after $\alpha$-conotoxin [Y11A] GI washout (Figure 4D). However, we noticed that $10 \mu \mathrm{M}$ GI exhibited higher affinity on heteromeric $\alpha 1 \beta 1 \delta \varepsilon \mathrm{nAChR}$, and the inhibitory ACh-evoked current of GI was only completely reversible over $9 \mathrm{~min}$ after $\alpha$-conotoxin GI washout (Figure 4C). Table 1 summarizes the recovery time after blockade by $\alpha$-conotoxin GI and its analogues.

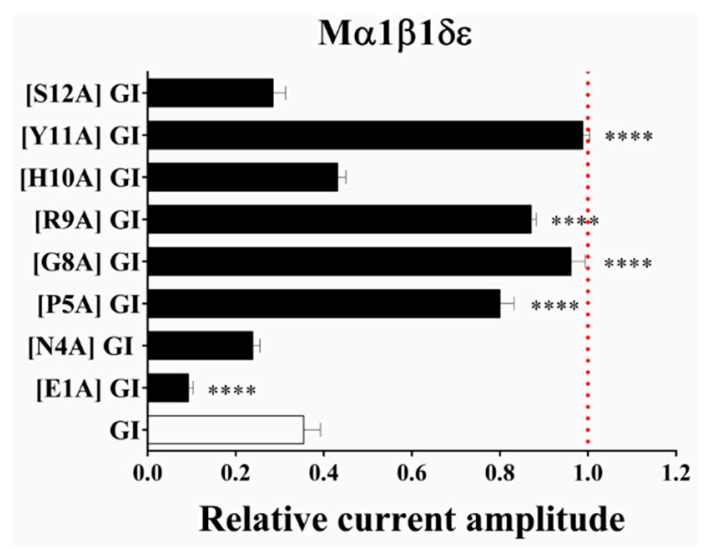

Figure 3. The effect on mouse $\alpha 1 \beta 1 \delta \varepsilon$ expressed in Xenopus laevis oocytes by GI and alanine-substituted analogues. A bar graph of inhibition of mouse $\alpha 1 \beta 1 \delta \varepsilon$ by GI and alanine variants. One-way analysis of variance scatter illustrating the loss or increase in the activity of alanine variants $(10 \mathrm{nM})$ compared to wild peptide using Dunnett's multiple comparisons test. ${ }^{* * * *}$ indicates $p<0.0001$. All data represent mean \pm S.E.M, $n=4-6$.
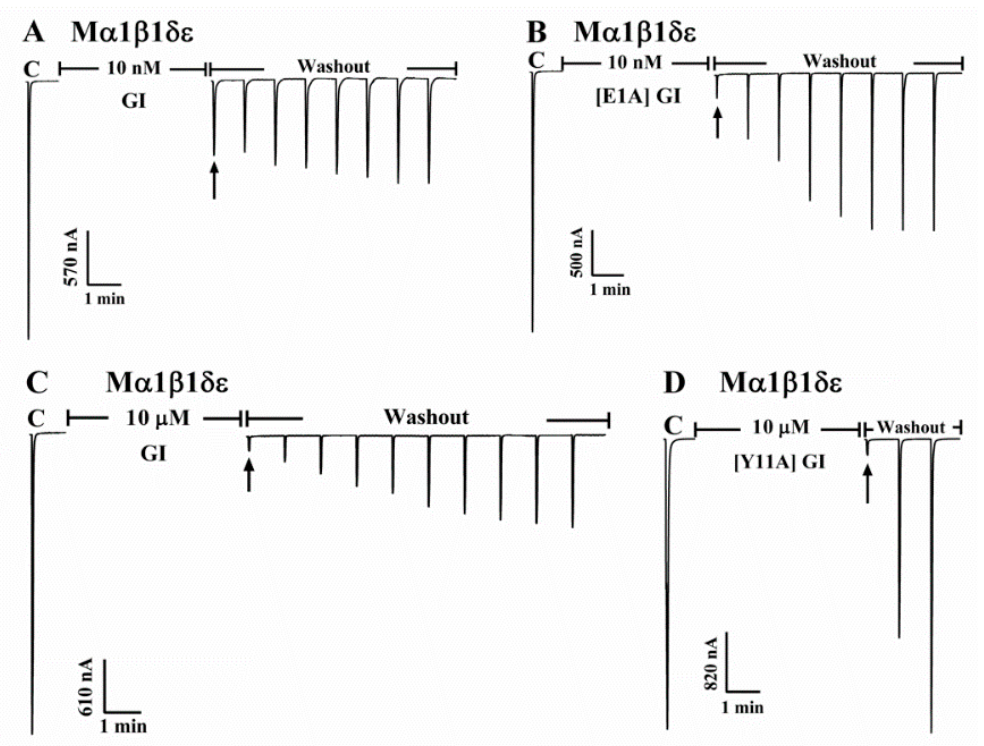

Figure 4. Blockade of mouse $\alpha 1 \beta 1 \delta \varepsilon$ nAChR by GI, [E1A] GI and [Y11A] GI. Representative current traces showing the inhibition of mouse $\alpha 1 \beta 1 \delta \varepsilon$ ACh-evoked currents by GI and [E1A] GI at the concentration of $10 \mathrm{nM}(\mathbf{A}, \mathbf{B}), \mathrm{GI}$ and [Y11A] GI at the concentration of $10 \mu \mathrm{M}(\mathbf{C}, \mathbf{D})$. Xenopus laevis oocytes expressing a given mouse $\alpha 1 \beta 1 \delta \varepsilon \mathrm{nAChR}$ were at a holding potential of $-70 \mathrm{mV}$ and were subjected to a $1 \mathrm{~s}$ pulse of ACh every minute as previously described [30]. After control responses to $\mathrm{ACh}$, the oocyte was exposed to toxins for $5 \mathrm{~min}$ (arrow). The toxin was then washed out and the response to ACh was again measured. "C" indicates control responses to ACh. 
Table 1. Recovery time after blockade by $\alpha$-Conotoxin GI and its analogues at the mouse $\alpha 1 \beta 1 \delta \varepsilon \mathrm{nAChR}$.

\begin{tabular}{cccc}
\hline Peptides (10 $\mathrm{nM})$ & $\mathrm{T}_{\mathbf{5 0}}{ }^{\mathbf{a}} \mathbf{( m i n )}$ & Peptides $(\mathbf{1 0} \mu \mathrm{M})$ & $\mathbf{T}_{\mathbf{9 5}}{ }^{\mathbf{b}}(\mathbf{m i n})$ \\
\hline GI & $>7$ & GI & $>9$ \\
{$[\mathrm{E} 1 \mathrm{~A}]$ GI } & 4 & {$[\mathrm{Y} 11 \mathrm{~A}] \mathrm{GI}$} & 2
\end{tabular}

a Time to $50 \%$ current amplitude recovery after toxin washout; GI and [E1A] GI were tested at a concentration of $10 \mathrm{nM} .{ }^{\mathrm{b}}$ Time to $95 \%$ current amplitude recovery after toxin washout; GI and [E1A] GI were tested at a concentration of $10 \mu \mathrm{M}$.

The concentration-response relationship of GI and its analogues were subsequently assessed on mouse $\alpha 1 \beta 1 \delta \varepsilon$ nAChR. Figure 5B and Table 2 summarizes that the four analogues [P5A] GI, [G8A] GI, [R9A] GI and [Y11A] GI reduced the activity significantly and the concentration-response curves of them shifted rightward relative to the native GI. The potencies of [P5A] GI and [R9A] GI were 9.3-fold and 8.5-fold lower than GI. [P5A] GI and [R9A] GI inhibited $\alpha 1 \beta 1 \delta \varepsilon$ nAChR with IC 50 of 54.72 and $49.79 \mathrm{nM}$ respectively (Figure $5 \mathrm{~B}$ and Table 2). Furthermore, the substitution of $\mathrm{Gly}^{8}$ and $\mathrm{Tyr}^{11}$ with Ala resulted in potencies more than 20-fold lower than GI. [G8A] GI and [Y11A] GI blocked muscle nAChR with $\mathrm{IC}_{50}$ of 170.60 and $381.20 \mathrm{nM}$ respectively (Figure 5B and Table 2). Strikingly, when we substituted $\mathrm{Glu}^{1}$ with Ala, the potency of [E1A] substantially increased with an $\mathrm{IC}_{50}$ of $1.83 \mathrm{nM}$ (5.85 nM in GI) (Figure 5A and Table 2). The other three mutations, [N4A] GI, [H10A] GI and [S12A] GI preserved similar activity, when compared to wildtype GI (Table 2). Above all, our results demonstrated that a single amino acid substitution in GI had a significant impact on its activity.

A $\quad$ M $\alpha 1 \beta 1 \delta \varepsilon$

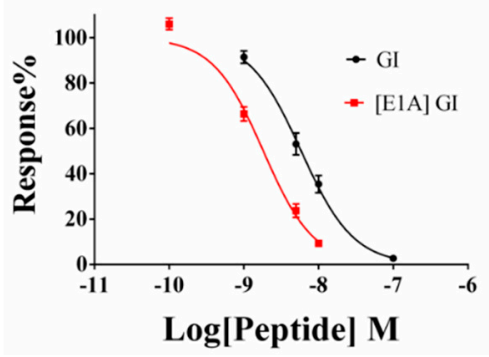

B $\quad$ M $\alpha 1 \beta 1 \delta \varepsilon$

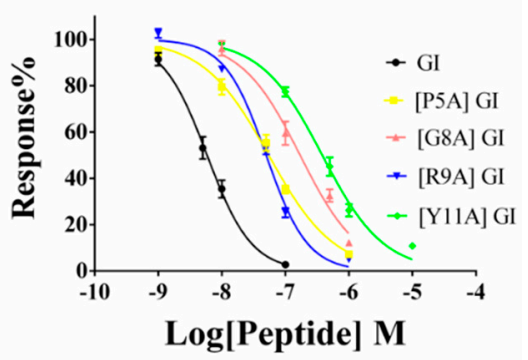

Figure 5. The concentration-response curves of mouse $\alpha 1 \beta 1 \delta \varepsilon$ nAChR subtype for GI and alanine-substituted analogues. (A) The concentration-response curves for GI and [E1A] GI. peptide [E1A] GI shifted the curves to the left, relative to the parent peptide GI. (B) The concentration-response curves for GI, [P5A] GI, [G8A] GI, [R9A] GI and [Y11A] GI. [P5A] GI, [G8A] GI, [R9A] GI and [Y11A] GI were towards the right compared to the native GI. All data represent mean \pm S.E.M, $n=7-10$.

Table 2. $\mathrm{IC}_{50}$ and Hill slope values for inhibiting mouse $\alpha 1 \beta 1 \delta \varepsilon$ subtype by $\alpha$-conotoxin GI and its analogues.

\begin{tabular}{cccc}
\hline Name & IC $_{\mathbf{5 0}}(\mathbf{n M}) * \boldsymbol{\alpha} \mathbf{1} \mathbf{1 \delta \varepsilon}$ & $\mathbf{n H}$ & $\mathbf{I C}_{\mathbf{5 0}}$ Ratio Relative to GI \\
\hline GI & $5.86(5.01-6.86)$ & $1.24(0.93-1.55)$ & 1.0 \\
[E1A] GI & $1.83(1.55-2.15)$ & $1.28(1.06-1.51)$ & 0.3 \\
[N4A] GI & $4.66(4.19-5.18)$ & $1.49(1.23-1.76)$ & 0.8 \\
[P5A] GI & $54.72(46.85-63.91)$ & $0.84(0.71-0.97)$ & 9.3 \\
[G8A] GI & $170.60(134.60-216.30)$ & $0.94(0.74-1.13)$ & 29.1 \\
[R9A] GI & $49.79(45.22-54.81)$ & $1.34(1.13-1.54)$ & 8.5 \\
[H10A] GI & $7.62(6.78-8.57)$ & $1.04(0.88-1.20)$ & 65.1 \\
[Y11A] GI & $381.20(323.40-449.40)$ & $0.90(0.76-1.05)$ & 0.9 \\
[S12A] GI & $5.39(4.72-6.15)$ & $1.28(1.01-1.55)$ & \\
\hline
\end{tabular}

$\mathrm{IC}_{50}$ and $\mathrm{nH}$ indicates half inhibitory concentration and Hill Slope respectively. ${ }^{*}$ indicates numbers in parentheses are $95 \%$ confidence intervals. 


\subsection{Potency of $\alpha$-Conotoxin GI and Its Analogues at the Rat Neuronal nAChRs}

Next, GI and above critical analogues were tested on other neuronal nAChR subtypes with high concentrations. $\mathrm{Glu}^{1}, \mathrm{Pro}^{5}, \mathrm{Gly}^{8}, \mathrm{Arg}^{9}$ and $\mathrm{Tyr}^{11}$ harboring a substitution to Ala exhibited no activity on $\alpha 3 \beta 2, \alpha 3 \beta 4, \alpha 4 \beta 4$ and $\alpha 7$ subtypes even up to $10 \mu \mathrm{M}$ (Figure 6). Interestingly, the inhibition of GI was $50 \%$ at the concentration of $10 \mu \mathrm{M}$ and GI blocked ACh-evoked current of $\mathrm{r} \alpha 9 \alpha 10 \mathrm{nAChR}$ with an $\mathrm{IC}_{50}$ of $9.35 \mu \mathrm{M}$ (Figure 7A and Table 3). Moreover, the potencies of [P5A] GI and [G8A] GI increased 2.1-fold and 2.2-fold compared to GI with the $\mathrm{IC}_{50}$ of 4.14 and $4.21 \mu \mathrm{M}$ respectively (Figure 7 and Table 3). In contrast, replacing Glu ${ }^{1}$ with Ala led to lower inhibitory activity on $\mathrm{r} \alpha 9 \alpha 10 \mathrm{nAChR}$.

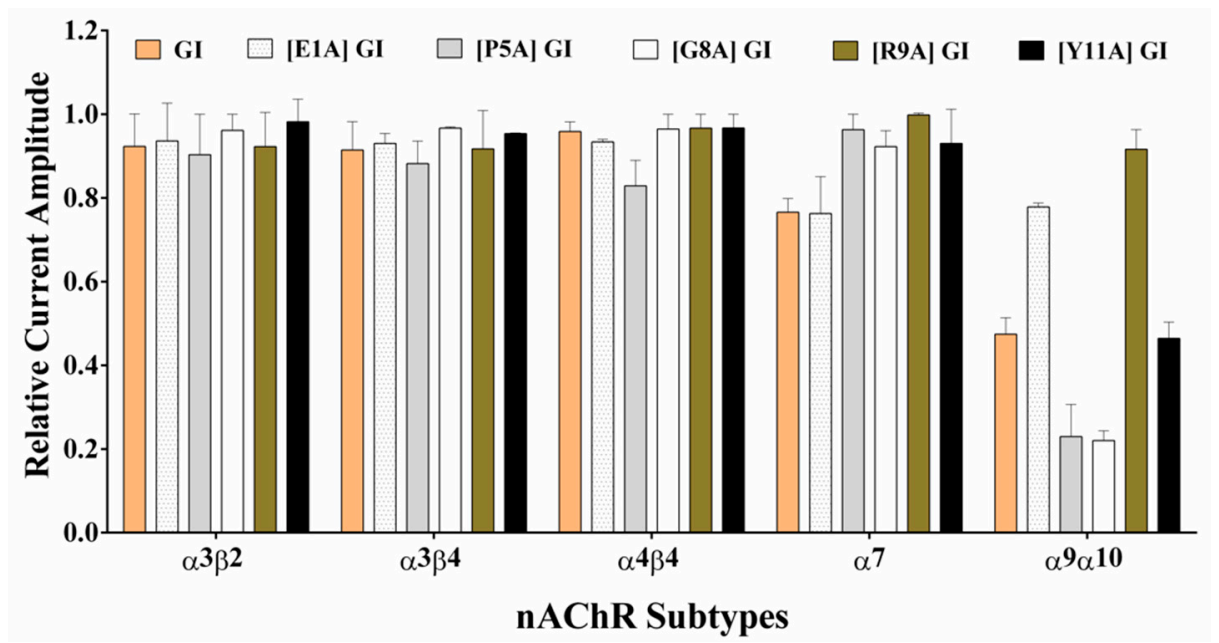

Figure 6. The effect of GI and alanine analogues on different nAChR subtypes expressed in Xenopus laevis oocytes. These mutations were determined at the concentration of $10 \mu \mathrm{M}$. A bar graph of the inhibition of nAChR subtypes by GI and its analogues. All data represent mean \pm S.E.M, $n=4-6$.
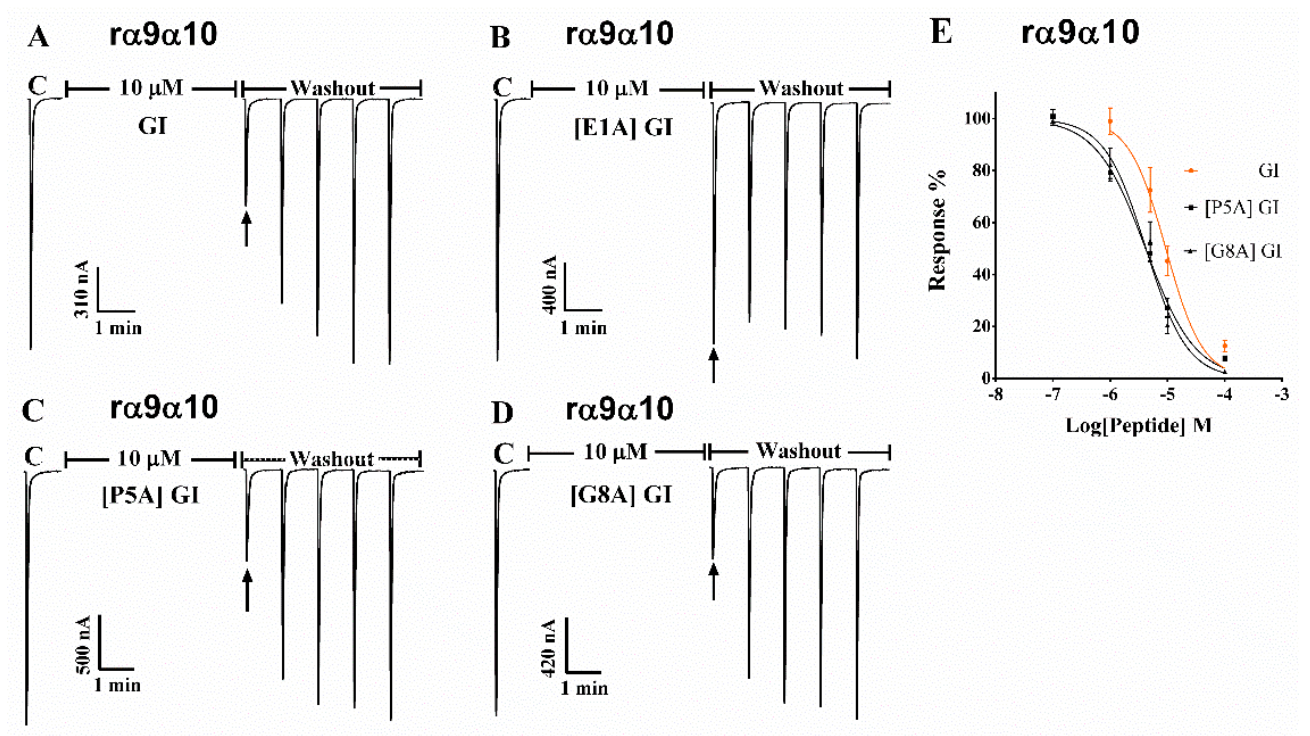

Figure 7. $\alpha$-conotoxin GI and its analogues were tested on neuronal rat $\alpha 9 \alpha 10 \mathrm{nAChR}$ subtype expressed in Xenopus laevis oocytes. The representative current traces showing the inhibition of rat $\alpha 9 \alpha 10$ ACh-evoked currents by GI (A), [E1A] GI (B), [P5A] GI (C) and [G8A] GI (D) respectively. Oocytes were clamped at $-70 \mathrm{mV}$ holding potential, and membrane currents were evoked with $10 \mu \mathrm{M}$ ACh. The inhibition of GI, [E1A] GI and [P5A] GI for rat $\alpha 9 \alpha 10 \mathrm{nAChR}$ was $48.4 \%, 10.5 \%, 72.3 \%$ and $69.8 \%$ at the concentration of $10 \mu \mathrm{M}$ respectively. (E) Concentration-response curves for GI, [P5A] GI and [G8A] GI. All data in (E) represent mean \pm S.E.M, $n=5-8$. 
Table 3. $\mathrm{IC}_{50}$ and Hill slope values for inhibiting neuronal rat $\alpha 9 \alpha 10 \mathrm{nAChR}$ subtype by $\alpha$-conotoxin GI and three mutants.

\begin{tabular}{cccc}
\hline Name & IC $_{\mathbf{5 0}}(\boldsymbol{\mu M}){ }^{*} \mathbf{r} \boldsymbol{\alpha} \mathbf{9} \boldsymbol{\alpha 1 0}$ & $\mathbf{n H}$ & IC $_{\mathbf{5 0}}$ Ratio Relative to GI \\
\hline GI & $9.35(7.02-12.5)$ & $1.35(0.57-2.15)$ & 1 \\
\hline$[\mathrm{E} 1 \mathrm{~A}] \mathrm{GI}$ & $>10$ & - & - \\
\hline$[\mathrm{P} 5 \mathrm{~A}] \mathrm{GI}$ & $4.14(3.42-5.03)$ & $1.01(0.79-1.22)$ & 0.4 \\
\hline$[\mathrm{G} 8 \mathrm{~A}] \mathrm{GI}$ & $4.21(3.21-5.51)$ & $1.20(0.83-1.59)$ & 0.5 \\
\hline
\end{tabular}

$\mathrm{IC}_{50}$ and $\mathrm{nH}$ indicates half inhibitory concentration and Hill slope respectively. ${ }^{*}$ indicates numbers in parentheses are $95 \%$ confidence intervals.

\subsection{Homology Modeling and Molecular Dynamic Simulation}

Molecular models of the interaction between the $\alpha 1(+) \delta(-)$ binding site and GI were established. The model was refined using molecular dynamics simulations; this was used to illuminate the SAR (Figure 8). According to the model, Glu ${ }^{1}$ is surrounded by two cysteines (Cys ${ }^{176}$ and Cys ${ }^{177}$ in $\alpha 1$ subunit) forming disulfide (Figure 8A). Meanwhile, only one amino acid, Glu ${ }^{147}$ in the $\delta$ subunit was found to act with $\mathrm{Glu}^{1}$, which would produce electrostatic repulsion. When $\mathrm{Glu}^{1}$ was substituted by Ala, the repulsive force between them decreased, contributing to a three-fold increased blockade of $\alpha 1 \beta 1 \delta \varepsilon$ nAChR. Among all analogues, [Y11A] GI had the highest decrease at the potency on $\alpha 1 \beta 1 \delta \varepsilon$ nAChR. Through $40 \mathrm{~ns}$ dynamic stimulation, $\mathrm{Tyr}^{11}$ is impacted by more amino acids in the $\delta$ subunit, including Leu ${ }^{93}$, $\mathrm{Tyr}^{95}$ and Leu ${ }^{103}$ (Figure 8B) forming a relatively hydrophobic environment. Replacing polar residue $\mathrm{Tyr}^{11}$ with a hydrophobic Ala significantly perturbed the affinity potency of GI to the $\delta$ subunit, explaining the activity loss of [Y11A] GI to $\alpha 1 \beta 1 \delta \varepsilon$ nAChR.
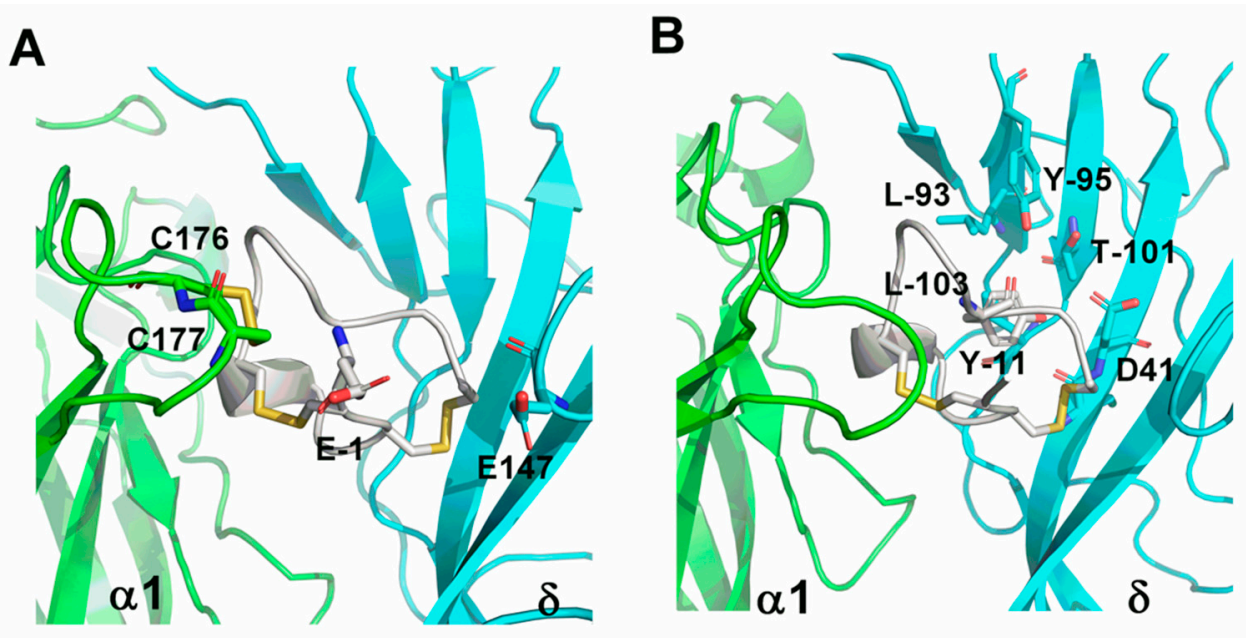

Figure 8. MD stimulations indicate the binding modes of GI to the interface of $\alpha \delta$ subunit respectively. (A) Amino acids around $5 \AA$ radius of the Glu-1 of GI are labeled. (B) Amino acids around $4 \AA$ radius of the Tyr-11 of GI are labeled. The $\alpha 1(+)$ subunit is shown in green, $\delta(-)$ subunit in cyan and the peptides GI in white.

\section{Discussions}

Until now, several conotoxins have been reported as muscle-type nAChRs inhibiters. The selected conotoxins from different conus species that targeted muscle-type nAChRs are summarized in Table 4 . So far, five different families targeting the muscle-type nAChRs have been identified, including $\alpha$-conotoxins, $\alpha \mathrm{B}$-conotoxins, $\alpha \mathrm{D}$-conotoxins, $\alpha \mathrm{O}$-conotoxins and $\alpha \mathrm{S}$-conotoxins, among which $\alpha-3 / 5$ conotoxins become dominant with their high affinity and selectivity. Some conotoxins of other families also inhibited muscle $n A C h R s$ but with less selectivity. For example, $\alpha B-V x X X I V A$ cloned from Conus vexillum inhibited mouse $\alpha 1 \beta 1 \delta \varepsilon \mathrm{nAChR}$ and rat $\alpha 9 \alpha 10 \mathrm{nAChR}$ with the $\mathrm{IC}_{50}$ of $6.6 \mu \mathrm{M}$ and 
$1.2 \mu \mathrm{M}$, respectively [31,32]. Another conotoxin cloned from Conus generalis, named $\alpha \mathrm{O}-\mathrm{GeXVIA}$, blocked various $\mathrm{nAChR}$ subtypes with nanomolar potency, including rat $\alpha 9 \alpha 10 \mathrm{nAChR}$ and mouse $\alpha 1 \beta 1 \delta \varepsilon$ nAChR [33]. Moreover, two other conotoxins also cloned from Conus generalis, named $\alpha \mathrm{D}$-GeXXA and $\alpha \mathrm{O}-\mathrm{GeXXVIIA}$, blocked muscle-type nAChR and neuronal nAChRs [34,35].

The fetal muscle-type nAChRs contain two ligand binding sites located at the extracellular domain, $\alpha / \gamma$ or $\alpha / \delta$ interface. The specific binding sites of these conotoxins have aroused attention, and several conotoxins were used to investigate the binding affinity on the $\alpha / \gamma$ or $\alpha / \delta$ interface $[20,36]$. Firstly, three $\alpha$-conotoxins, GI, MI and SIA conferred 10,000 -fold greater affinity at the $\alpha / \delta$ versus $\alpha / \gamma$ interface of muscle nAChR on BC3H-1 cells $[20,37,38]$. On the contrary, they displayed a higher affinity at the $\alpha / \gamma$ interface for Torpedo nAChR [39-41]. Hann et al. revealed that GI and MI exhibited similar physiological potencies on mouse $\mathrm{nAChR}$ while $\alpha$-conotoxin SI was much less effective than them [21]. In addition, SI failed to discriminate between the $\alpha / \gamma$ and $\alpha / \delta$ interface on mouse and Torpedo nAChR compared with GI or MI [21]. Previous investigation revealed that $\alpha$-AC1.1b(CIA) from Conus achatinus strongly preferred the $\alpha / \delta$ interface instead of the $\alpha / \gamma$ binding site on the mouse muscle nicotinic acetylcholine receptor [42]. Recently, Giribaldi et al. revealed that CIA also blocked the neuronal rat $\alpha 3 \beta 2 \mathrm{nAChR}$ with micromolar potency [43]. As we know, $\alpha-4 / 7$-conotoxin was generally regarded as targeting various neuronal nAChRs, however, one $\alpha-4 / 7$-conotoxin EI isolated from Conus ermineus was identified as selectively targeting the $\alpha / \delta$ interface of the Torpedo muscle-type nAChRs [44], another $\alpha-4 / 7$-conotoxin Lo1a has been characterized to differentiate between muscle-type nAChRs and neuronal-type nAChRs, and this conotoxin had a higher affinity at the $\alpha / \varepsilon$ interface [45]. Interestingly, $\alpha$ A-conotoxin OIVB with six cysteines isolated from Conus obscurus venoms from Indo-Pacific, exhibited 1800-fold lower affinity for adult muscle nAChRs, and this toxin preferentially bound to the $\alpha / \gamma$ interface [46]. Whereas $\psi$-conotoxin PrIIIE, with CysI-CysIV, CysII-CysV, and CysIII-CysVI disulfide configuration displays higher potency against the adult subtype than the fetal subtype nAChR $[47,48]$.

The structure of GI was revealed by NMR spectroscopy and X-ray crystallography $[19,24,49]$. A right-handed helical turn containing an $\mathrm{Asn}^{4}-\mathrm{Cys}^{7} \beta$-turn in the Gly ${ }^{8}$ to $\mathrm{Tyr}^{11}$ region is a typical structural feature of GI [24]. Gray et al. assumed that the shape of peptide GI was a triangular slab with $\mathrm{Glu}^{1}$, $\mathrm{Pro}^{5}$ and $\mathrm{Arg}^{9}$ situated at the corner [24]. As we know, the proline of loop1 in many $\alpha$-conotoxins is conservative, and this amino acid plays a crucial role in $3_{10}$-helix turn forming of conotoxins. Furthermore, Dutertre et al. demonstrated that $3_{10}$-helix turn might play a crucial role in defining both the ligand conformation and receptor-binding activity [50]. Olivera, B. $\mathrm{M} \mathrm{el}$ al. found that substituting Pro with Ala in $\alpha$-conotoxin MI dramatically reduced the toxin's potency at the $\alpha / \delta$ site [51]. Similarly, the $\operatorname{Pro}^{5}$ mutation in GI might alter $\beta$-turn secondary structures, significantly reducing the activity of $\alpha 1 \beta 1 \delta \varepsilon$ nAChR. Moreover, when we replaced $\mathrm{Gly}^{8}{ }^{8} \mathrm{Arg}^{9}$ and $\mathrm{Tyr}^{11}$ with Ala, three analogues, [G8A] GI, [R9A] GI and [Y11A] GI, suffered respectively 29.1-fold, 8.5-fold and 65.1-fold loss of their potencies on $\alpha 1 \beta 1 \delta \varepsilon \mathrm{nAChR}$ compared to GI, suggesting that the substitution of $\mathrm{Gly}^{8}$, Arg ${ }^{9}$ and $\mathrm{Tyr}^{11}$ with Ala probably had a significant impact on the right-handed helical turn. Meanwhile, $\mathrm{Tyr}^{11}$ in $\alpha$-conotoxin GI was located at a general hydrophobic pocket by molecular modeling, and we also noticed that it interacts with hydrophobic amino acids, including Leu ${ }^{93}$, $\mathrm{Tyr}^{95}$ and $\mathrm{Leu}^{103}$ in the $\delta$ subunit (Figure $8 \mathrm{~B}$ ), which is consistent with previous studies that showed $\alpha$-conotoxin MI interacted strongly with the $\delta$ subunit $[40,41]$. Janes, $R$. $W$ et al. also suggested that a hydrophobic phenylalanine in this position contributed to anchoring to the receptor [52]. In contrast to the loss of inhibitory activity at most alanine substitutions, Glu ${ }^{1}$ replaced by Ala in $\alpha$-conotoxin GI substantially improved the functional activity at $\alpha 1 \beta 1 \delta \varepsilon$ nAChR.

In addition, we observed a different current recovery time after the blockade by $\alpha$-conotoxin GI, [E1A] GI and [Y11A] GI at the mouse $\alpha 1 \beta 1 \delta \varepsilon$ nAChR, suggesting that single amino acid mutation possibly changed the interaction between ligands and receptors. Further research is needed in order to elucidate the molecular mechanism underlying their interaction. Various neuronal nAChRs, including $\alpha 3 \beta 2, \alpha 3 \beta 4, \alpha 4 \beta 4, \alpha 7$, and $\alpha 9 \alpha 10$ were also screened. The electrophysiology assay indicated that 
alanine-substituted analogues failed to inhibit these receptors, except for $\alpha 9 \alpha 10$. GI, [P5A] GI and [G8A]GI retained their activity at $\alpha 9 \alpha 10$ at the micromole level. In contrast, [E1A] GI had little influence on $\alpha 9 \alpha 10 \mathrm{nAChR}$ at a high concentration, and the selectivity of [E1A] GI at muscle $\alpha 1 \beta 1 \delta \varepsilon$ versus neuronal $\alpha 9 \alpha 10 \mathrm{nAChR}$ was improved compared to wildtype GI.

Table 4. The sequences of conotoxins from different species of cone snails blocked muscle-type nAChRs.

\begin{tabular}{|c|c|c|c|c|}
\hline Conotoxin & Resource & Sequence & Target & Reference \\
\hline$\alpha-G I$ & C. geographus & ECCNPACGRHYSC* & muscle & {$[17,18]$} \\
\hline$\alpha$-MI & C. magus & GRCCHPACGKNYSC* & muscle & [51] \\
\hline$\alpha$-SI & C. striatus & ICCNPACGPKYSC* & muscle & [52] \\
\hline$\alpha$-SIA & C. striatus & YCCHPACGKNFDC* & muscle & [20] \\
\hline$\alpha-\mathrm{AC} 1.1 \mathrm{~b} / \mathrm{CIA}$ & C. achatinus & NGRCCHPACGKHFSC* & muscle, $\alpha 3 \beta 2$ & {$[42,43]$} \\
\hline$\alpha$-EI & C. ermineus & RDOCCYHPTCNMSNPQIC* & $\begin{array}{l}\text { muscle, } \alpha 3 \beta 4 \\
\alpha 3 \beta 2, \alpha 4 \beta 2\end{array}$ & {$[44]$} \\
\hline$\alpha$-Lo1a & C. longurionis & EGCCSNPACRTNHPEVCD & $\alpha 7, \alpha 3 \beta 4$, muscle & [45] \\
\hline$\alpha \mathrm{A}-\mathrm{OIVB}$ & C. obscurus & CCGVONAACHOCVCKNTC* & muscle & [46] \\
\hline$\alpha \mathrm{B}-\mathrm{VxXXIVA}$ & C. vexillum & $\begin{array}{l}\text { VRCLEKSGAQPNKLFRPPCCQKG } \\
\text { PSFARHSRCVYYTQSRE* }\end{array}$ & $\alpha 9 \alpha 10$, muscle & {$[31,32]$} \\
\hline \multirow[t]{2}{*}{$\alpha \mathrm{D}-\mathrm{GeXXA}$} & \multirow[t]{2}{*}{ C. generalis } & DVHRPCQSVRPGRVWGKCCLT & \multirow{2}{*}{$\begin{array}{l}\alpha 9 \alpha 10, \alpha 7, \alpha 3 \beta 4, \\
\alpha 3 \beta 2, \\
\text { muscle }\end{array}$} & \multirow[t]{2}{*}{ [34] } \\
\hline & & $\begin{array}{l}\text { RLCSTMCCARADCTCVYHTW } \\
\text { RGHGCSCVM }^{*}\end{array}$ & & \\
\hline \multirow[t]{2}{*}{$\alpha \mathrm{O}-G e X V I A$} & \multirow[t]{2}{*}{ C. generalis } & TCRSSGRYCRSPYDRRRRYCRRITD & \multirow{2}{*}{$\begin{array}{l}\alpha 9 \alpha 10, \alpha 7, \alpha 3 \beta 4, \\
\alpha 3 \beta 2, \\
\text { muscle }\end{array}$} & \multirow[t]{2}{*}{ [33] } \\
\hline & & $\mathrm{ACV}^{*}$ & & \\
\hline$\alpha \mathrm{O}-\mathrm{GeXXVIIA}$ & C. generalis & $\begin{array}{l}\text { ALMSTGTNYRLLKTCRGSGRYC } \\
\text { RSPYDCRRRYCRRISDACV* }\end{array}$ & $\alpha 9 \alpha 10$, muscle & [35] \\
\hline 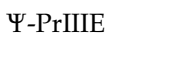 & C. parius & $\begin{array}{l}\text { AARCCTYHGSCLKEK } \\
\text { CRRKYCC* }\end{array}$ & muscle & {$[47,48]$} \\
\hline
\end{tabular}

For all conotoxins, an asterisk denotes a carboxyl-terminal carboxamide; $\mathrm{O}$ and $\gamma$ indicates Hydroxyproline and $\gamma$-carboxyglutamate (Gla).

\section{Materials and Methods}

\subsection{Peptide Synthesis and Oxidative Folding of $\alpha$-Conotoxin GI and Its Analogues}

All the $\alpha$-conotoxin GI and its analogues' linear peptides were successfully synthesized using Fmoc chemistry and standard side protection, except for four cysteines [30]. The cysteine residues were orthogonally protected using the acid liable S-trityl groups and the acid-stable S-acetomedomethyl groups. After cleavage of the assembled peptide chain from the resin, the first disulfide bond (the S-trityl groups on CysI and CysIII) in each peptide was formed by incubating the peptides in $5 \mathrm{mM}$ ferricyanide ( $\mathrm{pH} 7.5,0.2 \mathrm{mg} / \mathrm{mL}$ ) $45 \mathrm{~min}$ at $25^{\circ} \mathrm{C}$. The second disulfide bond (S-acetomedomethyl groups on CysII and CysIV) was formed by incubating peptides in $0.4 \mathrm{mM}$ $\mathrm{I}_{2}(0.4 \mathrm{mg} / \mathrm{mL}) 1 \%$ TFA under nitrogen protection conditions for $10 \mathrm{~min}$. Then the reaction was quenched by adding $1 \mathrm{M}$ ascorbic acid until the mixture became colorless. The peptide was purified by preparative RP-HPLC. Analytical RP-HPLC and electrospray-mass spectroscopy (ESI-MS) confirmed the purity and molecular mass of oxidized peptides.

\subsection{Peptide Quantification}

The concentration of purified $\alpha$-conotoxin GI and its analogues was quantified using an absorbance measurement with a spectrophotometer at a wavelength of $280 \mathrm{~nm}$, calculated with the Lambert-Beer equation, $\mathrm{a}=\varepsilon \mathrm{cl}$. Where $\mathrm{A}$ is the absorbance, $\varepsilon$ is the extinction coefficient, $\mathrm{l}$ is the cuvette path length, $\mathrm{c}$ indicates the concentration, and $\varepsilon$ is determined with the peptide properties calculator.

\section{3. cRNA Preparation and Injection into Xenopus laevis Oocytes}

Capped RNA (cRNA) for the various subunits were prepared using the mMESSAGE mMACHINE in vitro transcription Kit (Ambion, Austin, TX, USA) following linearization of the plasmid. The cRNA was purified using MEGA clearTm Transcription Clean-up Kit (Ambion, Austin, TX, USA). 
The concentration of each cRNA was confirmed by Smart Spec ${ }^{\mathrm{TM}}$ plus Spectrophotometer (Bio-Rad, Hercules, CA, USA), with the absorbance monitored at $260 \mathrm{~nm}$. Oocytes were extracted from mature female Xenopus laevis as described previously [30]. cRNAs of mouse $\alpha 1, \beta 1, \delta, \varepsilon$ subunits were mixed at 2:1:1:1 ratio with the final concentration of approximately $50 \mathrm{ng} / \mu \mathrm{L}$ for each subunit cRNA. $50.6 \mathrm{~nL}$ of this mixture was injected into each Xenopus lavies oocyte using a Drummond microdispenser (Drummond Scientific, Broomall, PA, USA), and then were incubated at $17{ }^{\circ} \mathrm{C}$ in ND96 buffer (96.0 mM NaCl, $2.0 \mathrm{mM} \mathrm{KCl}, 1.8 \mathrm{mM} \mathrm{CaCl}_{2}, 1.0 \mathrm{mM} \mathrm{MgCl}_{2}, 5 \mathrm{mM}$ HEPES, pH 7.1-7.5) supplemented with $10 \mu \mathrm{g} / \mathrm{mL}$ of penicillin, $10 \mu \mathrm{g} / \mathrm{mL}$ of streptomycin and $100 \mu \mathrm{g} / \mathrm{mL}$ of gentamicin before recording. Oocytes were injected within 1 day of harvesting and recordings were carried out 2-7 days after microinjection.

\subsection{Two-Electrode Voltage Clamp Electrophysiological Recordings of nAChRs Expressed in Xenopus laevis Oocytes}

Two-electrode voltage-clamp recordings from oocytes were carried out at room temperature using an Axonclamp 900A amplifier (molecular devices crop., Sunnyvale, CA, USA). The voltage-recording and current-injecting electrodes were pulled with borosilicate glass and had a resistance of 5-50 megaohms when supplemented with $3 \mathrm{M} \mathrm{KCl}$. The concentration of $\mathrm{ACh}$ was $10 \mu \mathrm{M}$ trials with $\alpha 1 \beta 1 \delta \varepsilon$ and $\alpha 9 \alpha 10$ subtypes, $200 \mu \mathrm{M}$ trials with $\alpha 7$, and $100 \mu \mathrm{M}$ for all other subtypes. Oocytes were exposed to a $50 \mu \mathrm{L}$ cylindrical oocyte recording chamber fabricated from Sylgard, and it was gravity-perfused with ND96 buffer at a rate of $\sim 2 \mathrm{~mL} / \mathrm{min}$. All toxin solutions also contained $0.1 \mathrm{mg} / \mathrm{mL}$ bovine serum albumin to reduce nonspecific adsorption of the peptide. During recording, the oocytes were clamped at a holding potential of $-70 \mathrm{mV}$. Oocytes were gravity-perfused with standard ND96 solution and supplied once per minute with one second ACh pulse. As a stable baseline was achieved, either ND96 alone or ND96 containing varying concentrations of GI and its analogues were perfusion-applied in a static bath for $5 \mathrm{~min}$ before the agonist $\mathrm{ACh}$ was added. The electrophysiology data were recorded and analyzed using Clampfit 10.2 software (Molecular Devices Corp., Sunnyvale, CA, USA).

\subsection{Data Analysis}

The effects of $\alpha$-conotoxin GI and its analogues on ACh-evoked nAChR-mediated currents were defined as peak current amplitudes relative to the average peak current amplitudes of three control ACh applications, and this was used to normalize the amplitude of each test response to obtain a "\% response" or "\% block". The concentration-response curves were fit to the pooled data by Equation (1).

$$
\% \text { response }=100 /\left\{1+\left([\text { toxin }] / \mathrm{IC}_{50}\right)^{\mathrm{nH}}\right\} .
$$

where $\mathrm{nH}$ is the slope factor (Hill slope) and $\mathrm{IC}_{50}$ is the peptide concentration that gave $50 \%$ inhibition of the maximal response. All the electrophysiological data were statistically analyzed using GraphPad Prism 6, with significant differences between the control GI and the analogues determined by t-test.

\subsection{Molecular Modeling, Docking, and Dynamic Simulation}

We resolve to clarify the molecular mechanism of GI and its analogues acting with muscle-type nAChRs. To begin, we constructed homology models of $\alpha 1$ and $\delta$ subunit with the program Modeler 9v10. Nicotinic acetylcholine receptor (code: 2BG9) from Torpedo was adopted as the template [53], and the interface was formed using Lymnaea stagnalis acetylcholine-binding protein (Ls-AChBP; PDB code: 1I9B) as the template [54]. Then the models were optimized with energy minimized by 100 ps of a standard molecular dynamic process with Gromacs 5.1. The structures of GI and its analog [Y11A] GI were used to dock to the $\alpha 1 \delta$ nAChR interface using the program FlexpepDock. All dynamic simulations were performed using Gromacs 5.1. Each dynamic simulation 
was performed for $40 \mathrm{~ns}$. The interatomic contact difference plot was calculated by determining the total number of toxin contacts with $4 \AA$ of each receptor residue.

\section{Conclusions}

In summary, we identified SAR between GI and the mouse $\alpha 1 \beta 1 \delta \varepsilon$ nAChRs using an alanine-scan strategy. To be specific, peptide [E1A] GI selectively inhibited mouse $\alpha 1 \beta 1 \delta \varepsilon$ nAChRs with better potency than native GI. Furthermore, [E1A] GI reduced the potency of neuronal $\alpha 9 \alpha 10$ nAChRs subtype and improved its selectivity on mouse muscle nAChRs. Compared to wildtype GI, four peptides i.e., [P5A] GI, [G8A] GI, [R9A] GI and [Y11A] GI displayed a dramatic loss of activity at the mouse $\alpha 1 \beta 1 \delta \varepsilon$ nAChR. Meanwhile, molecular dynamic simulations demonstrate a relatively hydrophobic Tyr ${ }^{11}$ of GI, a critical residue, binding with the $\delta$ subunit at the mouse $\alpha 1 \beta 1 \delta \varepsilon$ nAChR. For neuronal nAChRs, only two variants, [P5A] GI and [G8A] GI, have a slight increase at the $\alpha 9 \alpha 10$ $\mathrm{nAChR}$ versus GI. Taken together, our work expanded our knowledge on SAR between GI and the muscle-type nAChRs, providing sufficient data for the redesign of GI analogues with higher affinity and selectivity.

Supplementary Materials: The following are available online at http:/ / www.mdpi.com/1660-3397/16/12/507/ s1, Figure S1: The HPLC chromatograms and mass spectrum of GI, [E1A] GI and [N4A] GI respectively; Figure S2: The HPLC chromatograms and mass spectrum of [P5A] GI, [G8A] GI and [R9A] GI respectively; Figure S3: The HPLC chromatograms and mass spectrum of [H10A] GI, [Y11A] GI and [S12A] GI respectively.

Author Contributions: J.N., Y.W., and S.L. conceived and designed the experiments; J.N., Y.W. and R.L. performed the experiments; J.R. and Y.W. verified this experiment; J.N., X.Z., J.R., Y.W., D.Z. and S.L. analyzed the data; J.N., Y.W. and S.L. wrote the paper.

Funding: This research was funded by National Natural Science Foundation of China (No. 81660585, No. 31760249 and No. 81872794), Major International Joint Research Project of National Natural Science Foundation of China (81420108028), Hainan University Youth foundation (hdkyx201725), Changjiang Scholars and Innovative Research Team in University Grant (IRT_15R15).

Conflicts of Interest: The authors declare no conflict of interest.

\section{References}

1. Hurst, R.; Rollema, H.; Bertrand, D. Nicotinic acetylcholine receptors: From basic science to therapeutics. Pharmacol. Therapeut. 2013, 137, 22-54. [CrossRef] [PubMed]

2. Lebbe, E.K.; Peigneur, S.; Wijesekara, I.; Tytgat, J. Conotoxins Targeting Nicitinic Acetylcholine Receptor: An Overview. Mar. Drugs 2014, 12, 2970-3004. [CrossRef] [PubMed]

3. Mir, R.; Karim, S.; Kamal, M.A.; Wilson, C.M.; Mirza, Z. Conotoxins: Structure, Therapeutic Potential and Pharmacological Applications. Curr. Pharm. Des. 2016, 22, 582-589. [CrossRef] [PubMed]

4. Kalamida, D.; Poulas, K.; Avramopoulou, V.; Fostieri, E.; Lagoumintzis, G.; Lazaridis, K.; Sideri, A.; Zouridakis, M.; Tzartos, S.J. Muscle and neuronal nicotinic acetylcholine receptors. Structure, function and pathogenicity. FEBS J. 2007, 274, 3799-3845. [CrossRef] [PubMed]

5. Rogers, R.S.; Nishimune, $\mathrm{H}$. The role of laminins in the organization and function of neuromuscular junctions. Matrix Biol. 2017, 57-58, 86-105. [CrossRef] [PubMed]

6. Saxena, A.; Stevens, J.; Cetin, H.; Koneczny, I.; Webster, R.; Lazaridis, K. Characterization of an anti-fetal AChR monoclonal antibody isolated from a myasthenia gravis patient. Sci. Rep. 2017, 7, 14426. [CrossRef] [PubMed]

7. Mott, M.; Luna, V.M.; Park, J.Y.; Downes, G.B.; Epley, K.; Ono, F. Expressing acetylcholine receptors after innervation suppresses spontaneous vesicle release and causes muscle fatigue. Sci. Rep. 2017, 7, 1674. [CrossRef]

8. Ching, K.H.; Burbelo, P.D.; Kimball, R.M.; Clawson, L.L.; Corse, A.M.; Iadarola, M.J. Recombinant expression of the nAChR- $\alpha 1$ subunit for the detection of conformation-dependent epitopes in Myasthenia Gravis. Neuromuscul. Disord. 2011, 21, 204-213. [CrossRef]

9. Olivera, B.M.; Teichert, R.W. Diversity of the neurotoxic Conus peptides: A model for concerted pharmacological discovery. Mol. Interv. 2007, 7, 251-260. [CrossRef] 
10. Luo, S.; Zhu, X.; Wu, Y.; Zhangsun, D. Conotoxins and Drug Discovery with Special Reference to Hainan Species. In Toxins and Drug Discovery; Springer: Heidelberg, Germany, 2017; pp. 149-187.

11. Azam, L.; McIntosh, J.M. $\alpha$-Conotoxins as pharmacological probes of nicotinic acetylcholine receptors. Acta Pharmacol. Sin. 2009, 30, 771-783. [CrossRef]

12. Albuquerque, E.X.; Pereira, E.F.; Alkondon, M.; Rogers, S.W. Mammalian nicotinic acetylcholine receptors: From structure to function. Physiol. Rev. 2009, 89, 73-120. [CrossRef] [PubMed]

13. Robinson, S.D.; Norton, R.S. Conotoxin gene superfamilies. Mar. Drugs 2014, 12, 6058-6101. [CrossRef] [PubMed]

14. Dao, F.-Y.; Yang, H.; Su, Z.-D.; Yang, W.; Wu, Y.; Hui, D.; Chen, W.; Tang, H.; Lin, H. Recent Advances in Conotoxin Classification by Using Machine Learning Methods. Molecules 2017, 22, 1057. [CrossRef]

15. Muttenthaler, M.; Akondi, K.B.; Alewood, P.F. Structure-activity studies on $\alpha$-Conotoxins. Curr. Pharm. Des. 2011, 17, 4226-4241. [CrossRef] [PubMed]

16. Akondi, K.B.; Muttenthaler, M.; Dutertre, S.; Kaas, Q.; Craik, D.J.; Lewis, R.J.; Alewood, P.F. Discovery, synthesis, and structure-activity relationships of Conotoxins. Chem. Rev. 2014, 114, 5815-5847. [CrossRef] [PubMed]

17. Gray, W.R.; Luque, A.; Olivera, B.M. Peptide Toxins from Conus geographus Venom. J. Biol. Chem. 1981, 256, 4734-4740. [PubMed]

18. Johnson, D.S.; Martinez, J.; Eigoyhen, A.B.; Heinemann, S.F.; McIntosh, J.M. $\alpha$-Conotoxin ImI exhibits subtype-specific nicotinic acetylcholine receptor blockade: Preferential inhibition of homomeric alpha 7 and alpha 9 receptors. Mol. Pharmacol. 1995, 48, 194-199.

19. Pardi, A.; Galdes, A.; Florances, J.; Maniconte, D. Solution Structures of $\alpha$-Conotoxin GI Determined by Two-Dimensional NMR Spectroscopy. Biochemistry 1989, 28, 5494-5501. [CrossRef]

20. Groebe, D.R.; Dumm, J.M.; Levitan, E.S.; Abramson, S.N. alapha-Conotoxins selectively inhibited one of the two acetylcholine binding sites of nicotinic receptors. Mol. Pharmacol. 1995, 48, 105-111.

21. Hann, R.M.; Pagán, O.R.; Eterović, V.A. The $\alpha$-Conotoxins GI and MI Distinguish between the Nicotinic Acetylcholine Receptor Agonist Sites while SI Does not. Biochemistry 1994, 33, 14058-14063. [CrossRef]

22. Hann, R.M.; Pagán, O.R.; Gregory, L.M.; Jácome, T.; Eterović, V.A. The 9-arginine residue of alpha-Conotoxin GI is responsible for its selective high affinity for the alphagamma agonist site on the electric organ acetylcholine receptor. Biochemistry 1997, 36, 9051-9056. [CrossRef] [PubMed]

23. Groebe, D.R.; Gray, W.R.; Abramson, S.N. Determinants involved in the affinity of alpha-Conotoxins GI and SI for the muscle subtype of nicotinic acetylcholine receptors. Biochemistry 1997, 36, 6469-6474. [CrossRef] [PubMed]

24. Guddat, L.W.; Martin, J.A.; Shan, L.; Edmundson, A.B.; Gray, W.R. Three-Dimensional Structure of the $\alpha$-Conotoxin GI at 1.2 A Resolution. Biochemisty 1996, 35, 11329-11335. [CrossRef] [PubMed]

25. Gehrmann, J.; Alewood, P.F.; Craik, D.J. Structure Determination of the three Disulfide Bond Isomers of $\alpha$-Conotoxin GI: A Model for the Role of Disulfide Bonds in structural stability. J. Mol. Biol. 1998, 278, 401-415. [CrossRef] [PubMed]

26. Morrison, K.L.; Weiss, G.A. Combinatorial alanine-scanning. Curr. Opin. Chem. Biol. 2001, 5, $302-307$. [CrossRef]

27. Eustache, S.; Leprince, J.; Tuffery, P. Progress with peptide scanning to study structure-activity relationships: The implications for drug discovery. Expert Opin. Drugs 2016, 11, 771-784. [CrossRef]

28. Myers, R.A.; Cruz, L.J.; Rivier, J.E.; Olivera, B.M. Conus peptides as chemical probes for receptors and ion channels. Chem. Rev. 1993, 93, 1923-1936. [CrossRef]

29. Myers, R.A.; Zafaralla, G.C.; Gray, W.R.; Abbott, J.; Cruz, L.J.; Olivera, B.M. $\alpha$-Conotoxins, small peptide probes of nicotinic acetylcholine receptors. Biochemistry 1991, 30, 9370-9377. [CrossRef]

30. Luo, S.; Zhangsun, D.; Zhu, X.; Wu, Y.; Hu, Y.; Christensen, S. Characterization of a novel $\alpha$-Conotoxin TxID from Conus textile that potently blocks rat alpha3beta4 nicotinic acetylcholine receptors. J. Med. Chem. 2013, 56, 9655-9663. [CrossRef]

31. Loughnan, M.; Nicke, A.; Jones, A.; Schroeder, C.I.; Nevin, S.T.; Adams, D.J. Identification of a novel class of nicotinic receptor antagonists: Dimeric Conotoxins VxXIIA, VxXIIB, and VxXIIC from Conus vexillum. J. Biol. Chem. 2006, 281, 24745-24755. [CrossRef]

32. Luo, S.; Christensen, S.; Zhangsun, D.; Wu, Y.; Hu, Y.; Zhu, X. A Novel Inhibitor of alapha9alapha10 Nicotinic Acetylcholine Receptors from Conus vexillum Delineates a New Conotoxin Superfamily. PLoS ONE 2013, 8, e54648. 
33. Luo, S.; Zhangsun, D.; Harvey, P.J.; Kaas, Q.; Wu, Y.; Zhu, X. Cloning, synthesis, and characterization of $\alpha \mathrm{O}$-conotoxin GeXIVA, a potent alapha9alapha10 nicotinic acetylcholine receptor antagonist. Proc. Natl. Acad. Sci. USA 2015, 112, E4026-E4035. [CrossRef] [PubMed]

34. Xu, S.; Zhang, T.; Kompella, S.N.; Yan, M.; Lu, A.; Wang, Y. Conotoxin alphaD-GeXXA utilizes a novel strategy to antagonize nicotinic acetylcholine receptors. Sci. Rep. 2015, 5, 14261. [CrossRef] [PubMed]

35. Jiang, S.; Tae, H.S.; Xu, S.; Shao, X.; Adams, D.J.; Wang, C. Identification of a Novel O-Conotoxin Reveals an Unusual and Potent Inhibitor of the Human alpha9alpha10 Nicotinic Acetylcholine Receptor. Mar. Drugs 2017, 15, 170. [CrossRef] [PubMed]

36. Blount, P.; Merlie, J.P. Molecular Basis of the Two Nonequivalent Ligand Binding Sites of the Muscle Nicotinic Acetylcholine Receptor. Neuron 1989, 3, 349-357. [CrossRef]

37. Kreienkamp, H.J.; Sine, S.M.; Maeda, R.K.; Taylor, P. Glycosylation sites selectively interfere with alpha-toxin binding to the nicotinic acetylcholine receptor. J. Biol. Chem. 1994, 269, 8108-8114. [PubMed]

38. Luo, S.; McIntosh, J.M. Iodo-alpha-Conotoxin MI selectively binds the alpha/delta subunit interface of muscle nicotinic acetylcholine receptors. Biochemistry 2004, 43, 6656-6662. [CrossRef] [PubMed]

39. Bren, N.; Sine, S.M. Hydrophobic Pairwise Interactions Stabilize $\alpha$-Conotoxin MI in the Muscle Acetylcholine Receptor Binding Site. J. Biol. Chem. 2000, 275, 12692-12700. [CrossRef]

40. Sine, S.M.; Kreienkamp, N.B.; Maeda, R.; Taylort, P. Molecular Dissection of Subunit Interfaces in the Acetylcholine Receptor: Identification of Determinants of $\alpha$-Conotoxin MI Selectivity. Neuropharmacology 1995, 15, 205-211. [CrossRef]

41. Sugiyama, N.; Marchot, P.; Kawanishi, C.; Osaka, H.; Molles, B.; Sine, S.M. Residues at the Subunit Interfaces of the Nicotinic Acetylcholine Receptor That Contribute to $\alpha$-Conotoxin MI Binding. Mol. Pharmacol. 1998, 53, 787-794. [CrossRef]

42. Liu, L.; Chew, G.; Hawrot, E.; Chi, C.; Wang, C. Two Potent alapha-3/5 Conotoxins from Piscivorous Conus achatinus. Acta Biol. Biophys. Sin. 2007, 39, 438-444. [CrossRef]

43. Giribaldi, J.; Wilson, D.; Nicke, A.; Laconde, G.; Faucherre, A. Synthesis, Structure and Biological Activity of CIA and CIB, Two $\alpha$-Conotoxins from the Predation-Evoked Venom of Conus catus. Toxins 2018, 10, 222. [CrossRef] [PubMed]

44. Park, K.H.; Suk, J.E.; Jacobsen, R.; Gray, W.R.; McIntosh, J.M.; Han, K.H. Solution conformation of alpha-Conotoxin EI, a neuromuscular toxin specific for the alpha1/delta subunit interface of torpedo nicotinic acetylcholine receptor. J. Biol. Chem. 2001, 276, 49028-49033. [CrossRef] [PubMed]

45. Lebbe, E.K.; Peigneur, S.; Maiti, M.; Devi, P.; Ravichandran, S.; Lescrinier, E.; Ulens, C.; Waelkens, E.; D'Souza, L.; Herdewijn, P.; et al. Structure-function elucidation of a new $\alpha$-Conotoxin, Lo1a, from Conus longurionis. J. Biol. Chem. 2014, 289, 9573-9583. [CrossRef] [PubMed]

46. Teichert, R.W.; Rivier, J.; Torres, J.; Dykert, J.; Miller, C.; Olivera, B.M. A uniquely selective inhibitor of the mammalian fetal neuromuscular nicotinic acetylcholine receptor. J. Neurosci. 2005, 25, 732-736. [CrossRef] [PubMed]

47. Liuisma, A.O.; López-Vera, E.; Bulaj, G.; Watkins, M.; Olivera, B.M. Characterization of a novel $\Psi$-Conotoxin from Conus parius. Toxicon 2008, 51, 174-180. [CrossRef] [PubMed]

48. Mitchell, S.S.; Shon, K.J.; Foster, M.P.; Davis, D.R.; Olivera, B.M.; Ireland, C.M. Three-Dimensional Solution Structure of Conotoxin ४-PIIIE, an Acetylcholine Gated Ion Channel Antagonist. Biochemistry 1998, 37, 1215-1220. [CrossRef]

49. Maslennikov, I.V.; Sobol, A.G.; Gladky, K.V.; Lugovskoy, A.A.; Ostrovsky, A.G.; Tsetlin, V.I.; Ivanov, V.T.; Arseniev, A.S. Two distinct structures of $\alpha$-Conotoxin GI in aqueous solution. Eur. J. Biochem. 1998, 254, 238-247. [CrossRef]

50. Dutertre, S.; Lewis, R.J. Toxin insights into nicotinic acetylcholine receptors. Biochem. Pharmacol. 2006, 72, 661-670. [CrossRef]

51. Jacobsen, R.B.; DelaCruz, R.G.; Grose, J.H.; McIntosh, J.M.; Yoshikami, D.; Olivera, B.M. Critical Residues Influence the Affinity and Selectivity of $\alpha$-Conotoxin MI for Nicotinic Acetylcholine Receptors. Biochemisty 1999, 38, 13310-13315. [CrossRef]

52. Benie, A.J.; Whitford, D.; Hargittai, B.; Barany, G.; Janes, R.W. Solution structure of $\alpha$-Conotoxin SI. FEBS J. 2000, 476, 287-295. [CrossRef] 
53. Unwin, N. Refined structure of the nicotinic acetylcholine receptor at $4 \AA$ A resolution. J. Mol. Biol. 2005, 346, 967-989. [CrossRef] [PubMed]

54. Brejc, K.; Van Dijk, W.J.; Klaassen, R.V.; Schuurmans, M.; Smit, A.B.; Sixma, T.K. Crystal structure of an ACh-binding protein reveals the ligand-binding domain of nicotinic receptors. Nature 2001, 411, $269-276$. [CrossRef] [PubMed] 